\title{
On the Theory of The Symbiosis of Emotion and Reason of Xunzi
}

\author{
Wu Baohong \\ Teaches English at School of philosophy, \\ Beijing Normal University, Beijing,
}

China.

In Xunzi's thought, the noumenon self is the existence which is connected with all things on the basis of Dao. It is the existence of the integrity of emotional desire, intellectual ability, willpower and social behavior ability. Therefore, the pursuit of emotional desire or intellectual rationality can not achieve the real self. The realization of self is the same process as people's understanding of Tao. It is not natural. It needs to eliminate the rudimentary and accumulate the etiquette and righteousness to support emotion. Therefore, Xunzi's negation of the attitude and behavior of only obeying the sexual desire and the emphasis on the hypocrisy of the way of doing Li and Yi by heart are aimed at highlighting the fact that the ontological self remains to be completed and the existence of individual life coexists with emotion and reason.

The ontological self of the symbiosis of reason and sense which from the perspective of Dao Xunzi thought that Dao is the existence of integrity through all things. That is to say, "all things are one side of the Tao, and one thing is one side of all things." (Xunzi tianlun)Dao is the root of all things, and all things are the manifestation of Dao. Accordingly, only on the basis of penetrating all things can man form a correct understanding of Dao. Dao is the basis of all things, and it is expressed through the constant changes of things. Dao often changes in many ways, which requires people to grasp the essence of Dao through a systematic effort and complex representation. In fact, people's recognition of Dao and self realization are the same process. This view is mainly manifested in the following two aspects.

On the one hand, from the point of view that Qi is the origin of the generation of the universe, human beings have knowledge and meaning, and they are in the relationship of continuity and sensibility which are different from and unified with all things. Xunzi said "water and fire have Qi but not life, plants have life but ignorance, and animals have perception but no righteousness. People have spirit, life, perception and righteousness, so they are most valuable in the world. " (Xunzi wangzhi )There are many similarities between human beings and other animals. The difference is that human beings have the ability to consciously understand the Dao and the emotion of liking morality. This makes people keep an open and creative way to get along with others and realize the unity of difference with all things. The reason why the sage can measure the ancient things according to his own experience and the individual people's situation according to the general state of man is that he has grasped the way that people communicate with all things and can analyze things according to the way that 
runs through all things. On the other hand, in terms of the structure of human being's existence, human being is the whole existence of perceptual ability, cognitive ability, willpower and social behavior ability. In the whole process of human's behavior, emotional desire, will and sociality must be displayed, and inevitably related to the cognition of the heart. This is what Xunzi said "xing(性)is what people are born to accomplish, emotion is the content of xing, and desire is the expression of emotion. Desire can be expressed as the pursuit of what people want to get. In the process of pursuing, people only pursue what their hearts approve. This is the reason that knowledge will inevitably appear in the process of human desire. "(Xunzi zhengming)Whether the mind can "know the Dao" depends on its autonomy. Because in Xunzi's thought, heart is a comprehensive existence which contains emotional desire and rational cognition. Whether the relationship between emotional desire and rationality can be harmonious or not depends on whether the heart of the emperor is self determined. In fact, the rational mind of the emperor is easily covered by the emotional desire of the officials. Because in the original state of pure and clear mind, which is not affected by things, it not only likes the interests, but also likes the morality, and the heart likes the interests as the basic physiological needs will be relatively strong. "In reality, people are born to like interests. If people follow their natural desires and do not govern rationally, there will be a phenomenon of competition without resignation. "That is to say, the pure state of the mind is occupied and disturbed by its emotional desire to like interests. This is one of the main contents of the discourse on xing e( 性? ). Therefore, in xunzi dalue, Yao and Shun can't get rid of the side that people want benefits, Jie Zhou can't get rid of the side that people like morality, and both like morality and pursue benefits lie in the existence of people. The reason why Yao and Shun became the king was that they correctly guided people's heart of liking morality and conquering the heart of pursuing interests.

It needs to be emphasized here that Xunzi's "xing"性 is aimed at the attitude and behavior of pure obedience to emotional desire, while the heart is much more complex than "xing". Dong Fangshuo, a modern Chinese scholar, pointed out that "Xunzi's mind is a general concept of function, which includes many different functions. It not only has obvious cognitive characteristics, but also has the function of dominating 'Heavenly organs' compared with five senses, but also has different functions such as will, emotion, desire, etc." ${ }^{[1]}$ In fact, in addition to the will power of discerning, knowing and being able to be one, the heart itself also has such emotional factors as discontent, "worry and fear", "peace and happiness" and "impetuosity". In addition, the rational ability of the heart to analyze the factors such as emotion and desire is latent, and its realization needs people's conscious efforts.In this regard, human's rational ability can not be called "xing", because its realization does not conform to Xunzi's definition of "sex" which is innate and can be completed naturally without efforts.

Another aspect of self existence that can not be ignored is human's sociality or the ability of social behavior. Xunzi believed that the individual finiteness of human determines that the solution of individual existence problems must be carried out in groups. For example, "Xunzi rich country" chapter points out that "people's life, can not be without groups, groups without division, then struggle, then chaos, then poverty."In 
the society, people's existence is in a harmonious and civilized state through the social behavior ability such as division of labor, exchange and cooperation. Since modern times, Xunzi's social analysis of human beings has been recognized by Yu Jiaju, LV Zhenyu, Guo Moruo, Zhang Dainian, Du Guoxiang and other scholars. As a matter of fact, the group nature of human beings makes it possible for individuals to overcome their narrow self-interest, which is an important factor that cannot be ignored in Xunzi's thoughts. Indeed, people's awareness of the realization of their own behavior in the way of group civilization means that people have consciously realized the connection and unity between themselves and others, which is an indispensable part of the process of people's identification to righteousness.

It can be seen from the above that man is a multi-level and multi-dimensional existence connected with the other, among which mental ability "knowing the Dao" is the key factor that makes the realization of his noumenon self possible. Because it can not only highlight the subjectivity of the individual, but also make it possible to realize the dialectical unity of self-knowledge and self love. The dialogue between Confucius and his disciples Zilu, Zigong and Yanyuan about what is "Shi"士, "shijunzi"士君子 and "mingjunzi" 明君子in "Xunzi Zidao" chapter shows that people's understanding of Dao is positively related to people's self realization. Purposeful "shi"士 strive to make others understand and love themselves. The shi junzi 士君子 can continuously improve their moral cultivation by virtue of etiquette and righteousness. As for the mingjunzi 明君子, they are aware of the "few perils" and fully understand the principle of the integration of external and internal, body and mind. For them, there is no longer a distinction between me and him, or between myself and Dao, but a state of selfconsciousness and freedom.

From the perspective of the realization of self existence, the "ming junzi"明君子 gentleman can truly realize the common and dialectical unity of reason, which is "the person who has truly realized the noumenon self". His concern is "what is self", not "what kind of person should I become".As Sun Wei said, "the practice of virtue is not the ultimate goal of Xunzi's ethics and philosophy. For him, the highest goal of man is Dao. " ${ }^{[2]}$ Furthermore, the aim of man's cultivation of Dao is to realize the whole self of noumenon. The particularity of human being is that its existence must realize the understanding of noumenon self through the civilized way of Li and Yi.

\section{The way to realize the symbiosis of human feelings and reason is etiquette and righteousness}

In Xunzi's thought, a person must try to interpret his life in the group by the way of civilization. That is to say, the way of $\mathrm{Li}$ and $\mathrm{Yi}$ is the way to interpret and realize human beings' common life.

$\mathrm{Li}$ and $\mathrm{Yi}$ are human laws created by sages of all ages according to the way of objective existence, which can meet people's emotional desire and psychological needs and enable the relationship between society and individuals to be properly handled.In this regard, Xunzi made a systematic exposition on the origin of rites.According to" Xunzi lilun "chapter, the most direct reason for making rites is that the first king dislikes the chaotic situation in which material and desire cannot be coordinated, so making rites to support people's desire, meet people's needs, and make people's desire and material develop harmoniously. At the same time, the creation of Li and Yi is based on the way 
of heaven and earth, and comes from the feelings of returning to the beginning of human kindness, that is, rites "serve heaven, serve the earth, respect the ancestors and honour the master" .

In short, etiquette and righteousness can not only make people's desires reasonably realized, but also meet people's spiritual needs of liking morality. Etiquette and righteousness come together with people's life. It originates from people's desire and the emotional and rational needs of the group. It flourishes in the middle right way, which is rich in form and content, and finally connects with the freedom state of the Dao.

From the perspective of the existence of individual life, rites run through the principles of people's life, such as the awareness of life and life's food, clothing, housing and transportation. They are the existence way of people's life to be reasonably realized. "Xunzi xiushen "chapter says: "a man without etiquette does not live. "People's health cannot be separated from etiquette and righteousness. " Where blood, will and mind are used, the rules of rites shall govern, and not the rules of rites shall prevail; food, drink, clothing, habitation, movement and stillness shall be governed by the rules of rites, and not the rules of rites shall lead to illness." Nourishes life by courtesy and righteousness. People can get along with each other in a harmonious way, so that the whole life state can be displayed in a reasonable way.

In fact, when the natural emotional desire is transformed into the moral rational emotion, the social and spiritual needs of people can also be realized. For example, "Xunzi Wangzhi"said: "you can't give up the meaning of Li and Yi. It can be called filial piety by etiquette, respect for elder brother by etiquette, obedience by etiquette, and monarch by etiquette. A monarch is a man who is good at managing people. If the monarch can exercise the principle of managing the masses well, everything will be suitable, all livestock will grow reasonably, and people will get what they deserve. " That is to say, etiquette and righteousness not only express people's feelings of loving relatives, respecting superiors, loving people and cherishing creatures, but also coordinate the relationship between individuals and groups, people and nature, and meet people's social and group needs. Zhang Dainian once pointed out: "how can people start to group? Xunzi thought that what the crowd needs most is etiquette and righteousness; there must be etiquette and righteousness, and then the crowd can consolidate. He thinks that the reason why Li and Yi are human beings, the so-called humanity, should give full play to the reason why people are human beings, should practice $\mathrm{Li}$ and $\mathrm{Yi} .{ }^{~}{ }^{[3]} \mathrm{It}$ is an inevitable way for human beings to realize their noumenon self by virtue of $\mathrm{Li}$ and $\mathrm{Yi}$. A gentleman is one who is good at using the way of $\mathrm{Li}$ and $\mathrm{Yi}$ to achieve self and others, and to realize the participation in the governance of heaven and earth. In short, etiquette and righteousness can not only support the body, but also the heart. The etiquette and righteousness connected with Dao can break people's narrow selfish side, awaken people's kindness and cultivate people's righteousness. Therefore, only by learning the $\mathrm{Li}$ and $\mathrm{Yi}$ can people really understand the unity of rites and music, achieve the state of governing Qi and nourishing heart, and realize the whole, essence and beauty connected with Dao. On the 
contrary, if we love ourselves and pursue the realization of ourselves in one-sided way without knowing the etiquette and righteousness, we can only lead to confusion in competition, and finally make our desires impossible to realize. The so-called "when people exercise ritual justice, they can get both desire and justice; if blind desire dominates themselves, they can get nothing." (Xunzi lilun)From the above analysis, we can see that the key to self achievement is not the "xing"性 of emotional desire, but whether the rationality of the heart can harmonize the emotional desire of people. The so-called "if the heart can be justified, though there are many desires, it will not hinder governance." If there is not so much desire to show such behavior, it is because of the heart calling behavior. If the mind doesn't recognize the truth of things correctly, even if there is little desire, it will lead to confusion. " (Xunzi zhengming)In fact, desire itself is not evil. Only because of the difference of "knowledge", which leads to different ways of people's pursuit of desire, can there be the difference between a gentleman and a villain. This is what "Xunzi honor and Disgrace" says: "the material knowledge and ability of a gentleman and a villain are the same. Both gentlemen and villains like honor and hate being humiliated. The reason why gentlemen and villains are different is that they pursue honor in different ways. "The different degree of people's understanding of the Dao leads to the different way of pursuing honor and profit. Therefore, in order to achieve the ontological self and give full play to the rational function of the mind to understand the Dao and practice the Dao, people need to work on the "reduction" of uncovering and the "increase" of accumulated learning.

\section{The kongfu of uncovering the confuse and understanding the truth}

Xunzi believed that people "all have the quality of knowing the right of benevolence, righteousness and law, and all have the quality of being able to know the right of benevolence, righteousness and law" (Xunzi xing e). Moreover, people's behavior will obey the heart's approval, that is, "desire is innate, and people will obey the heart's arrangement in the process of pursuing desire." (Xunzi Zhengming) But the ability of knowing of the mind does not naturally play a role in the process of understanding Dao. People often shelter their understanding of the whole Dao due to their understanding of something or their desire for something. That is to say, "the common disaster of the people in the world is unknown the Dao, which is the cause of people's great disaster." (Xunzi rongru) Therefore, to achieve a comprehensive understanding of the Dao, we need to work hard to uncover.

In reality, in the process of putting people's behavior into practice, the mind is very easy to be disturbed by material desire and other factors. Xunzi once pointed out: "the human mind is like a dish of water. If it is right and wrong without moving, then it will be turbid down and clear up, then it will be enough to see the man and the eyebrow and check the reason."

When the breeze is over, the clear and turbid move below, and the clear and disorderly move above, you can't get the right shape. So is the heart. " (Xunzi Jiebi) the human heart is like a plate of water, the breeze just blows gently, and the state of 
Qingming清明 is broken. Once the mind is in the state of being blinded, it will turn with things, indulgence and chaos. That is to say, if we follow the human feelings without think, there must be chaos and violence" (Xing $e$ ). If we want to reach the free state of connecting with Dao, we must have the gongfu of knowing the Dao.

In a word, only when people have the knowledge of "unity" can they really understand themselves. To realize the real understanding of the noumenon self, we need to keep the mind clear and calm in the process of continuous extension, increase and dynamic. In this sense, the process of uncovering is actually a process of self dissection, self reflection and the combination of mind and Fao. According to Gao Fang, "uncovering is not only about a correct way of thinking, but also a process of self disclosure and discovery, a process of introspective questioning about what kind of" I "is, and a process of conscious criticism of one's own living state." ${ }^{[4]}$ It can be said that being good at introspection is an important prerequisite for a deep understanding of oneself. To achieve this inner view of rationality, we need to do the following two aspects.

On the one hand, to keep a calm state of mind and keep the mind in a state of "emptiness", not only "erudition and daily self-examination", but also "not to be harmed by your own accumulation".Don't be stubborn and presumptuous, keep an open mind." When you see the good, you will cultivate yourself; when you see the bad, you will introspect yourself; when you are good, you will feel happy; when you are not good, you will feel disgusted." (Xunzi Xiushen )In a calm and clear state of mind, what likes kindness and dislikes goodness is a kind of inner emotion of human beings. It doesn't need external coercion, and naturally comes out from the inside.Conforming to things to achieve just right, understanding oneself will not blame others, understanding destiny will not blame God.

On the other hand, learn from the king and keep your mind focused on the Dao. In Xunzi's view, the holy king is a concrete practitioner of humanity. "Xunzi Jiebi荀子.解蔽" said: "learning to know where to stop. Where does it stop? Stop where humanity is at its best. So, what is the ultimate expression of humanity? This is the holy king. The sage shows the perfect relationship between human relations, and the King shows the human system very well. Only when the sage and the king are integrated can they be called the acme of the world. "The shortcut to realize the road is not to yearn for the supernatural power of the invisible sky, but to get close to the wise teachers, learn from the holy king, and maintain the unity of to the Dao.

Consciously cultivate the sincerity and adherence to the way of benevolence and righteousness."Xunzi bugou荀子.不苟" said, "the most important thing for a gentleman to nourish his heart is sincerity. To be sincere is to stick to benevolence and do justice."Sincerity" here refers to a kind of inner cultivation work of a gentleman, who is sincere in keeping benevolence and doing righteousness. And Shendu 慎独is to know the Dao and follow the Dao, and to stick to the state of inner oneness.Deng Xiaohu said: "as a kind of" true "state of mind, sincerity refers to the fact that the" heart "truly accepts" Dao "as a consistent guiding principle, and adheres to the essence of" benevolence and righteousness ". Therefore, it can adhere to" benevolence and righteousness "in" will and meaning ", and practice" benevolence and righteousness "in" body and action ", so as to achieve the unity of the inside and the outside." [5]"Shendu 慎独" in Xunzi's thought refers to a state of conscientious adherence to the 
inner unity of Dao. Sincerity and independence do not refer to the heart itself, but to the relationship between heart and Dao. In the gongfu of Shendu, the subject is mind, the object is the state of mind's concentration on Dao, and the purpose is the combination of mind and Dao.

In short, to be clear is to constantly reduce the cover, avoid narrow and simple, break the barrier between things and me, and make the use of emotional desire conform to the way naturally, so as to achieve a state of free and comprehensive development, that is, the state of great clearness and brightness. Wu Shuqin pointed out that "great Qingming" is not a state of omniscient knowledge of the world, but a state of freedom in which the mind can make things suitable for each other due to the natural separation and organization of things without the distortion of human beings. ${ }^{[6]}$ It can be said that Xunzi's "great Qingming大清明" state is not a mysterious state, but a free state connected with Dao through the practice of $\mathrm{Li}$ and $\mathrm{Yi}$.

\section{Accumulate etiquette and righteousness to support emotion}

Xunzi didn't agree to achieve "knowledge" by breaking away from the mystical idea of the life of $\mathrm{Li}$ and $\mathrm{Yi}$ or the practice of living in isolation, but advocated to realize people's emotional desire in a reasonable way in the group by actively learning the Dao of Li and Yi.That is to say, in" Xunzi ruxiao", self realization needs to "do things cautiously and treat customs carefully, so as to constantly realize good etiquette and righteousness habits".In the interaction with the environment, we should take seriously our own behavior, pay attention to the influence on customs and habits, keep accumulating good ideas, keep the dominant position on the environment, and form a good virtue.

Specifically, the positive effects of people's accumulating etiquette and righteousness on the environment and good customs on the formation of ideal personality are mainly reflected in the following two aspects.

On the one hand, the gentleman pays attention to constantly learning the Dao of etiquette and righteousness, and actively transforms people's natural emotional desire."Xunzi rongru " section: "ordinary people, the accumulation of good and all called saints." The key to what kind of person you are is whether you can accumulate etiquette and righteousness the day after tomorrow. The important difference between a gentleman and a villain is that they accumulate different things. The gentleman "accumulates the literature" the line of etiquette and righteousness, while the villain "accumulates the property" and "is at liberty". The so-called "real accumulation of force for a long time" means that the object of "accumulation" constantly affects the whole way of life existence of human beings, which eventually leads to different personalities. Therefore, Xunzi said, "it can be Yao, Yu, Jie, Zhi, craftsman, and farmers and businessmen, because of the different habits formed in the ordinary accumulation." Xunzi's emphasis on "accumulation" fully shows that only through accumulation of etiquette can we fully realize the subjectivity of the noumenon self.

On the other hand, the gentleman is good at using the way of $\mathrm{Li}$ and $\mathrm{Yi}$ to construct a fair and reasonable system and create a good social environment, which is conducive to self realization. Xunzi said "accumulation ? " is to pay attention to the 
influence of environment on people, and more emphasis on people's dominance of environment. A good human environment is very important for people's self realization. The so-called "Peng蓬 grows in hemp, and can grow very straight without support" (Xunzi quanxue). Therefore, the gentleman is good at drawing support from other things, with the help of the wisdom of the sages and kings in the whole history and the social environment of social fairness and justice to promote the cognition of the mind to the Dao. For example, Xunzi proposed that the gentlemen would choose a good human environment and get close to the wise teachers. Because the wise teachers can use the Dao of Li and Yi to guide the shaping of local customs. The so-called "Confucians improve politics in this dynasty, and beautify customs in the lower position." (Xunzi ruxiao )

From the above we know that only a gentleman who knows the Dao of Li and Yi can become the main governing body of all things. The so-called "Li and Yi are the beginning of governance; the gentleman is the beginning of Li and Yi. For it, through it, accumulate it, to be good, they are gentleman's beginning. Therefore, heaven and earth give birth to gentlemen, and gentlemen manage heaven and earth. " (Xunzi Wangzhi ) the gentleman takes the way of $\mathrm{Li}$ and $\mathrm{Yi}$ as his own way of existence. He realizes the way of $\mathrm{Li}$ and $\mathrm{Yi}$ voluntarily, and thus plays a role in governing all things in the world. In other words, it means that in the process of self realization of human being's noumenon, in the final analysis, human's free will plays a decisive role. Although the law of rites is made by sages, it is up to everyone to decide whether they can implement it voluntarily or not. If one doesn't understand the true meaning of morality, even a saint can't make him do something moral. For example, Yao and Shun could not educate people like Zhu and others. Therefore, "Zhu and Xiang do not change alone. It is not the fault of Yao and Shun, but the sin of Zhu and Xiang."

\section{Conclusion}

In Xunzi's thought, from the perspective of Dao, self is the coexistence of sensibility, intellect, willpower and social behavior. Emotion and reason are dialectically unified in the process of the realization of man's Noumenon life. Without emotional desire, rational lack of motivation, irrational emotional desire can not be reasonably realized. The Dao of $\mathrm{Li}$ and $\mathrm{Yi}$ is the way to realize the common sense. It is the basis of realizing the unity of knowledge and benevolence that self-consciousness can solve the tension between emotional desire and rationality, between individual and society by using the etiquette. If self love means the emergence of self-consciousness, then self love on the basis of "knowing the Dao" means the awakening of moral rationality. In a word, the realization of noumenon self is to integrate the understanding of the essence of self and others in the sense of Dao into the whole of life, so life is constantly transformed into the existence of the coexistence of emotion and reason with the unity of Dao. 


\section{Works Cited}

Dongfang Shuo: if there is no gentleman, the heaven and the earth will be ignored -Xunzi's theory of the relationship between mind and the Dao, Journal of ethics and public affairs, 2009 (0).

Sun Wei: an analysis of Xunzi's theory of "the Dao" -- from ritual and music to metaphysical way, Journal of Handan University, 2017(4).

Zhang Dainian, outline of Chinese philosophy, Beijing: China Social Sciences Press, 1982, P. 311.

Gao Fang: Xunzi's uncovering and self-discovery, Inner Mongolia Social Sciences (Chinese version), 2004 (3).

Deng Xiaohu: Sincerity and self construction of Xunzi, Journal of Handan University, 2016 (3).

Wu Shuqin: learning to connect the way of sages -- Xunzi's exhortation to learn, Journal of Qilu cultural studies, 2010. 